\title{
Modified Theory for the Characterization of Ionization Smoke Detectors
}

\author{
JEFFREY S. NEWMAN \\ Factory Mutual Research Corporation \\ 1151 Boston-Providence Turnpike \\ Norwood, Massachusetts 02062
}

\begin{abstract}
Ionization detectors have been characterized using a modified theory which includes a soot particle charge fraction functionality in addition to the generally accepted particle size and number density dependence. A sensitivity factor has been determined which, for a given detector, is influenced by both the fire combustion mode and fuel source. This factor decreases as the fuel bond unsaturation and aromaticity increases and can be predicted from the soot yield for flaming fires. An order of magnitude increase in sensitivity factor for wood accompanies the transition from non-flaming to flaming combustion mode and suggests a large charge fraction in non-flaming wood smoke aerosols. This result is similar to that found in flaming aromatics such as polystyrene, and is consistent with the general ionization detector experience showing an insensitivity to non-flaming fires.
\end{abstract}

KEYWORDS: Detection, Smoke Characterization

\section{INTRODUCTION}

Reliable fire detection is an essential aspect of fire protection in residential and industrial applications, both for the safe evacuation of people and for fire control or extinguishment. Assessment of the necessary detection response requires identification/quantification of: 1) the appropriate fire detector characteristics; 2) the environment generated by the fire; and 3) the fire hazard. Previous work [1,2] has presented a generalized response theory for fire detectors. In addition, the fire environment and fire hazard have been examined for selected applications, within a defined set of detection criteria.

In this paper, conventional ionization detector theory [3-5] has been modified to account for the sensitivity of ionization detectors to the variety of electrical charges carried by fire smoke aerosols. A method is also developed to predict ionization detector sensitivity from the soot yield of the fuel being burned. 


\section{DETECTOR RESPONSE THEORY}

In general, the response of a smoke detector can be treated as a first-order system coupled with a time lag, i.e.,

$$
\frac{d C_{s}}{d t}=\frac{1}{\tau}\left[C_{o\{(t-t)}-C_{s(t)}\right]
$$

where $t$ is the time in seconds; $\mathrm{C}_{\mathrm{g}}$ is the instantaneous smoke concentration measured by the detector at time $\mathrm{t} ; \mathrm{C}_{\mathrm{o}}$ is the "true" or reference concentration (outside the detector) at time ( $\mathrm{t}$ $\left.t_{1}\right) ; \tau$ is the detector time constant in seconds; and $t_{1}$ is the lag time in seconds. Two apparent detector characteristics, $\tau$ and $t_{1}$, can be noted in Eq.(1). $\tau$ can be thought of as the time constant for the specific sensor used in the detector, while $t_{1}$ is associated with a delay in smoke transport to the sensor such as through filters, sampling lines, etc.

Smoke detectors typically operate as either set-point or range devices. A set-point detector, as its name implies, is preset to respond at some specific level of smoke concentration, while a range detector is capable of giving concentration information over a range of smoke concentrations. Set-point detectors are considered as a special case of range detectors in the following discussion.

\section{IONIZATION DETECTOR RESPONSE}

Conventional ionization detector theory [3-5] provides the following relationship for detector response:

$$
y \cdot \text { constant }=N_{t} r_{m}
$$

where $N_{t}$ is the total number of smoke particles passing through the ionization chamber and $r_{m}$ is the characteristic particle size (given here as a most probable particle radius $(\mu \mathrm{m})[6,7]$ ). $\mathrm{y}$ is derived from the change in ionization chamber current, $\Delta \mathrm{I}$, and is given by the following two equations:

$$
\begin{aligned}
& y=x \frac{2-x}{1-x} \\
& x=\frac{\Delta I}{I_{0}}
\end{aligned}
$$

where $I_{o}$ is the initial current in the chamber. (The constant term in Eq.(2) is related to the specific characteristics of the ionization detector chamber). For reference, Table 1 gives $r_{m}$ values for a number of materials. 


\begin{tabular}{|c|c|c|}
\hline$(\mathrm{wel})$ & (1) & (x) \\
\hline \multirow{12}{*}{ 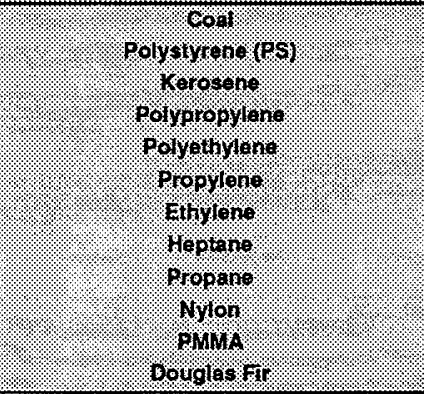 } & 0.078 & 0.067 \\
\hline & 0.078 & 0.129 \\
\hline & 0.073 & 0.067 \\
\hline & 0.079 & 0.054 \\
\hline & 0.077 & 0.042 \\
\hline & 0.076 & 0.063 \\
\hline & 0.072 & 0.015 \\
\hline & 0.077 & 0.025 \\
\hline & 0.068 & 0.017 \\
\hline & 0.075 & 0.064 \\
\hline & 0.068 & 0.014 \\
\hline & 0.062 & 0.002 \\
\hline \multicolumn{3}{|l|}{ 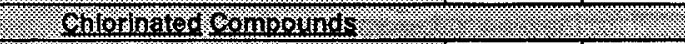 } \\
\hline \multirow{4}{*}{ 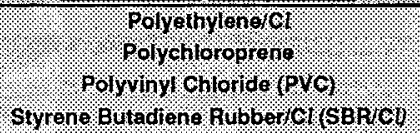 } & 0.090 & 0.134 \\
\hline & 0.090 & 0.099 \\
\hline & 0.083 & 0.090 \\
\hline & 0.073 & 0.122 \\
\hline
\end{tabular}

Modified from Reference 7.

\section{MEASUREMENTS}

Experiments were performed in the Factory Mutual Research Corporation (FMRC) $500 \mathrm{kW-}$ Scale Flammability Apparatus, which is shown schematically in Figure 1. Analog ionization

\section{Collection Hood}
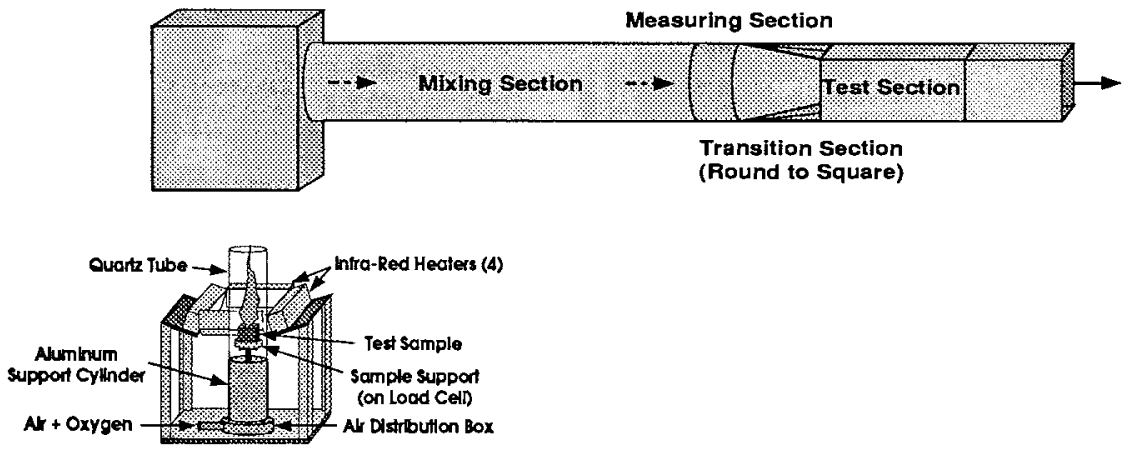

Figure 1. FMRC $500 \mathrm{~kW}$-Scale Flammability Apparatus. 
detectors were placed in the test section $(0.61-\mathrm{m} \times 0.61-\mathrm{m} \times 1.22-\mathrm{m}$ long) of the apparatus and monitored continuously during exposure to fire products from various fuels - wood (Douglas Fir), heptane, Pittsburgh seam coal, polyvinyl chloride (PVC), chlorinated styrene butadiene rubber (SBR/Cl) and polystyrene (PS). The gas velocity in the test section of the apparatus could be varied over the range of 0.5 to $5.0 \mathrm{~m} / \mathrm{s}$. Simultaneous measurements were made of carbon dioxide, carbon monoxide, oxygen, water and total hydrocarbon concentrations. A smoke turbidimeter was used to measure the optical density at three discrete wavelengths of the fire products, and a particulate mass monitor was used to measure concurrently the concentration of solid aerosols. The fuel mass loss rate was also continuously measured.

\section{RESULTS AND ANALYSIS}

The ionization detector responses were "calibrated" by introducing a step input of fire product aerosols from a $0.02 \mathrm{~m}^{2}$ heptane pan fire, using the following special case of Eq.(1):

$$
\frac{C_{s}}{C_{0}}=1-e^{-\left(t-t_{D}\right) / \tau}
$$

The simultaneous measurement of the response of three detectors, however, indicated no perceptible time constant, $\tau$, or lag time, $t_{1}$, over the velocity range of 0.5 to $5.0 \mathrm{~m} / \mathrm{s}$ and ambient temperature up to $60^{\circ} \mathrm{C}$.

From Eq.(2), a plot of $y$ versus the particle density $N_{1} r_{m}$ should yield a single curve for all types of smoke sources. However, as illustrated by Figure 2, this is not the case as several response curves result from invoking Eq.(2), with the two lines in the figure representing the outermost curves. The data are composites for three detectors (with the symbol size representative of the variation between detectors) and for a range of ventilation conditions with the fuels in a flaming combustion mode. $\mathrm{N}_{\mathrm{t}}$ was determined from the following relationship given in Reference 6:

$$
N_{t}=\frac{f_{v}}{18.62 r_{m}^{3}}
$$

where $f_{v}$ is the particulate volume fraction $\left(\mathrm{m}^{3}\right.$ particles $/ \mathrm{m}^{3}$ gas).

Apparently, an additional factor beyond $N_{t}$ and $r_{m}$ is contributing to the ionization detector response.

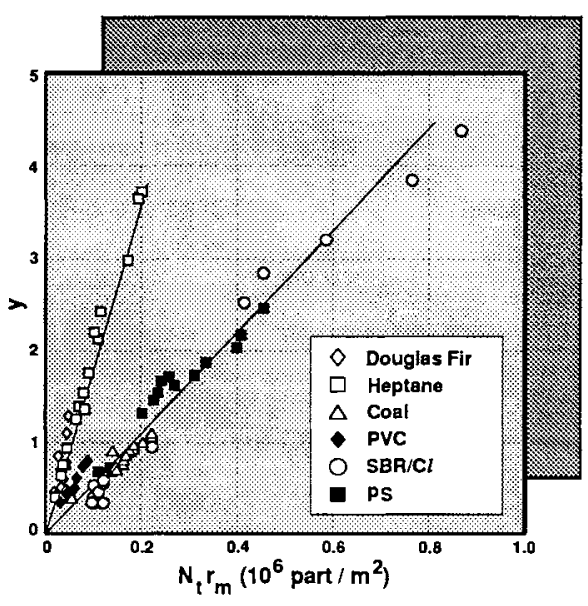

Figure 2. Ionization detector response versus particle density. 
Previous work [8] has measured the fraction of charged particles produced by the combustion of a number of materials, and has shown that particle charge depends strongly on the material burned. For example, flaming wood and heptane were shown to have a charge fraction, $X_{e}$, of 0.20 , while 0.80 was found for flaming polyurethane. The following modification of Eq.(2) to account for particle charge has been found to be consistent with the data:

$$
y \cdot \text { constant }=\left(1-X_{e}\right) N_{t} r_{m}
$$

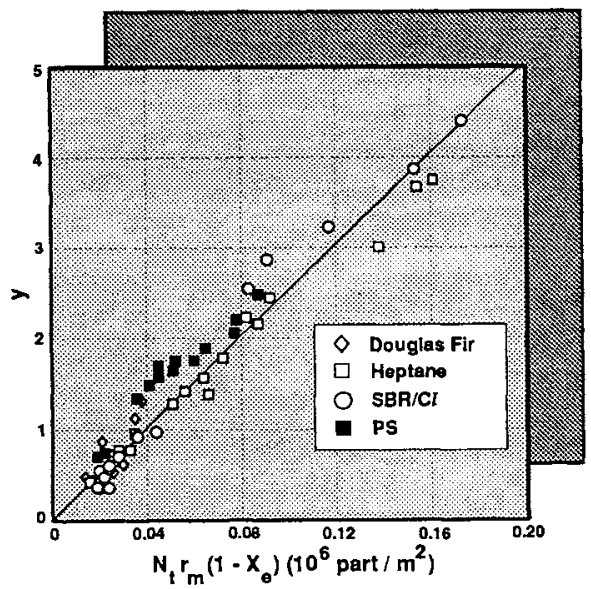

Figure 3 replots the data for Douglas Fir and heptane (using $X_{e}=0.20$ ) and polystyrene and chlorinated styrene butadiene rubber (using $X_{e}=0.80$ ). "The correlation is remarkable, indicating that ionization detectors are indeed sensitive to particle charge, resulting in a "discrimination" capacity. Unfortunately, Eq.(7) is difficult to apply, requiring knowledge of smoke particle numbers, size and charge entering the ionization chamber. Figure 4 reexamines the ionization detector response data in Figure 2 by plotting $y$ versus $f_{y}$, which essentially removes the particle size dependence and shows a wider data scatter. However, it can be noted that the response curves appear to be linear for a given fuel. Figure 5, illustrates that by using the slope, $\alpha$, of each curve in Figure 4 to characterize detector response, the response data can be collapsed into a single relationship given by:

$$
y=\alpha f_{v}
$$

Figure 3. Ionization detector response corrected for particle charge fraction.

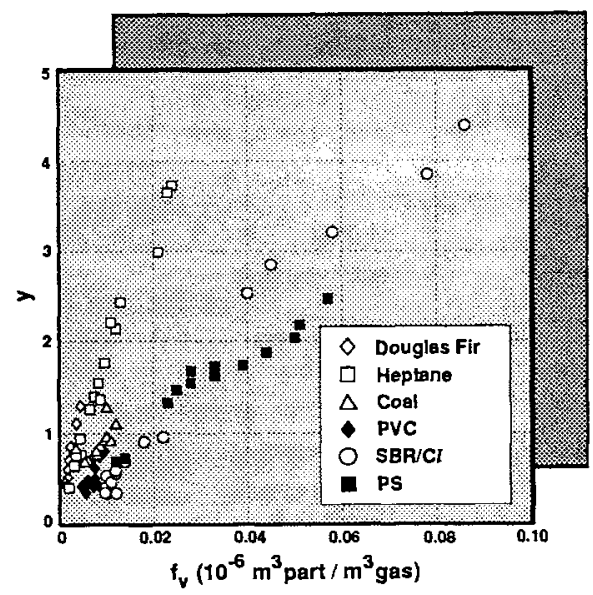

Figure 4. Ionization detector response versus soot volume fraction.

"The charge fraction found for polyurethane was applied to the polystyrene and chlorinated styrene butadiene rubber based upon similar chemical structures, i.e., unsaturated aromatics. 
where $\alpha$ is now defined as the detector/material sensitivity factor. Similarly, Figure 6 plots the ionization detector response for Douglas Fir, PVC and polystyrene under non-flaming conditions.

The $\alpha$ values, listed in Table 2, illustrate a reduced dependence of $\alpha$ on combustion mode as the fuel increases in bond unsaturation and aromaticity, such that the values for flaming and non-flaming polystyrene are essentially identical $(0.46$ versus $\left.0.50 \times 10^{8}\right)$. The order of magnitude decrease in $\alpha$ for Douglas Fir from 3.07 to $0.31 \times 10^{8}$, accompanying the transition from flaming to non-flaming combustion mode, suggests a large charge fraction in non-flaming wood smoke aerosols. This is supported by the 0.5 to 0.8 equilibrium charge fraction reported for smoke from smoldering wood fires [8] and is compatible with general ionization detector experience showing insensitivity to non-flaming fires such as from wood [9].

The sensitivity factor, $\alpha$, for flaming combustion is shown in Figure 7 to be related to the soot yield, $\mathrm{Y}_{\mathrm{s}}$ ( $\mathrm{g}$ soot/g fuel) given in Table 1, i.e.,

$$
\alpha=-\left[0.62 \ln \left(Y_{S}\right)+0.74\right] \times 10^{8}
$$

This result is not unexpected since the main source of ions in flames is due to chemi-ionization [10]. For fuels with increasing bond unsaturation and aromaticity, the chemi-ionization reaction and soot particle formation in the flame increase. For example, it has been shown that, as the total number density of ions derived from chemi-ionization decays, the

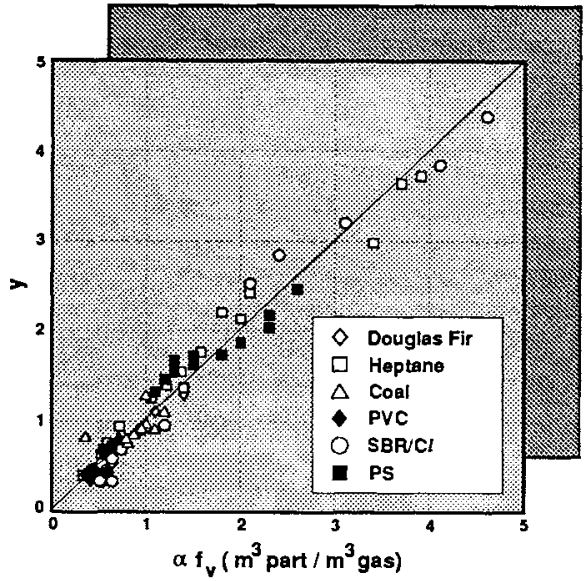

Figure 5. Ionization detector response versus normalized soot volume fraction.

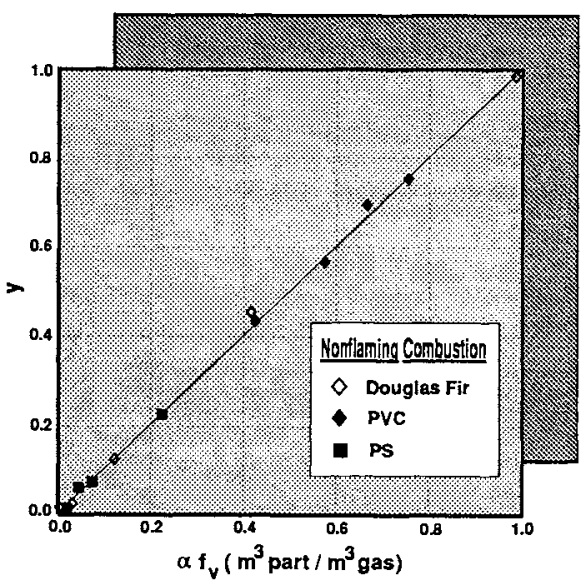

Figure 6. Ionization detector response versus normalized soot volume fraction for nonflaming fires. 


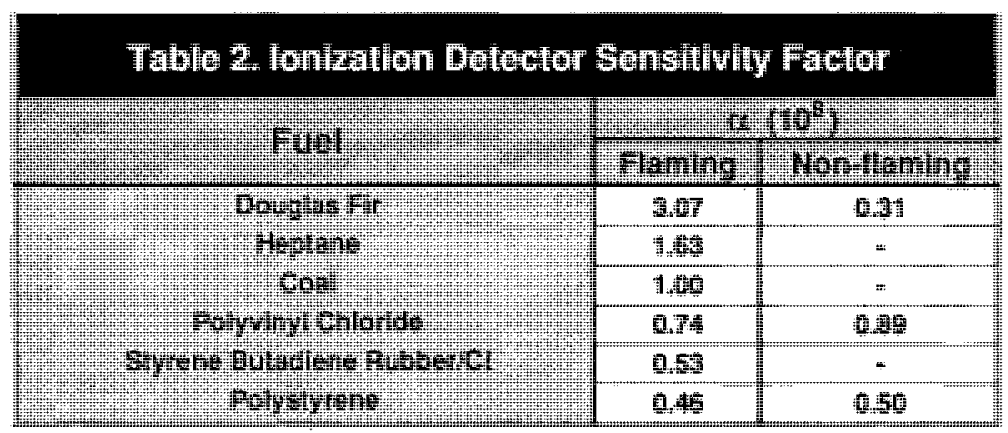

number density of neutral and charged soot particles increases in an acetylene/oxygen flame [11]. It has also been postulated that chemi-ions are the driving force behind soot nucleation [11]. Thus, the charge fraction of soot particles should increase as the soot yield increases. This is consistent with, for example, the decrease in $\alpha$ from $1.63 \times 10^{8}$ for saturated heptane to $0.46 \times 10^{8}$ for unsaturated aromatic polystyrene.

Therefore, knowledge of the fuel soot yield seems sufficient to predict the detector/material sensitivity factor, $\alpha$, for an ionization detector in response to a fuel in flaming combustion. Equation (8) can be used with the factor $\alpha$ to predict detector response versus either the particulate volume fraction, $f_{v}$, or the optical density using the following relationship developed in Reference 6:

$$
f_{v}=\frac{O D_{\lambda} \lambda}{7.0}
$$

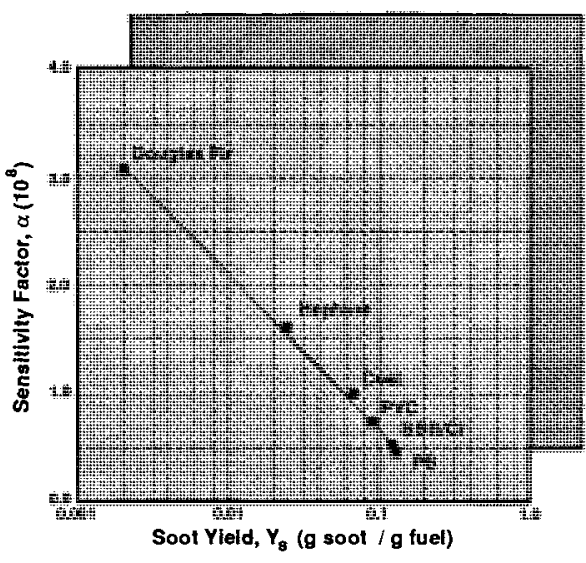

where $\mathrm{OD}_{\lambda}$ is the optical density $\left(\mathrm{m}^{-1}\right)$ at wavelength, $\lambda(\mu \mathrm{m})$.

\section{CONCLUDING REMARKS}

Figure 7. Ionization detector sensitivity factor versus soot yield.

Smoke particle charge effects explain deviations between observed ionization detector response behavior and existing theory. It is somewhat surprising that these charge effects were not noted previously. As early as 1967, detailed experiments demonstrated that soot particle growth in a flame can be controlled by electric fields [12] and, in 1971, the charge on soot particles from flames was observed [13]. This study concludes that ionization detector response is strongly dependent on soot particle charges influenced by both the 
combustion mode and the fuel being burned. The fuel soot yield, at least for flaming fires, appears to be controlled by similar mechanisms that determine soot particle charges. This results in a detector/material sensitivity factor for an ionization detector that can be predicted from the fuel soot yield.

\section{REFERENCES}

1. Newman, J.S., "Prediction of Fire Detector Response," Fire Safety Journal 12:205-211 (1987).

2. Newman, J.S., "Principles for Fire Detection," Fire Technology 24:116-127 (1988).

3. Hosemann, J.P., "Uber Verfahren zur Bestimmung der Korngrössenverteilung hockkonzentrierter Polydispersionen von MiePartikeln," Ph.D. Thesis, Aachen, 1970.

4. Scheidweiler, A., "The Ionization Chamber as Smoke Dependent Resistance," Fire Technology 12:113-123 (1976).

5. Helsper, C., Fissan, H., Muggli, J., and Scheidweiler, A., "Verification of Ionization Chamber Theory," Fire Technology 19:14-21 (1983).

6. Newman, J.S., and Steciak, J. "Characterization of Particulates from Diffusion Flames," Combustion and Flame 67:55-64 (1987).

7. Newman, J.S., and Steciak, J., "Particulate Generation from Diffusion Flames," Proceedings of the 1987 ASMEIJSME Thermal Engineering Conference, Honolulu, Hawaii, March 22-27, 1987.

8. Burtscher, H., Reis, A., and Schmidt-Ott, A., "Particle Charge in Combustion Aerosols," Journal of Aerosol Science 17:47-51 (1986).

9. Bertschinger, S., "Smoke Detectors and Unwanted Alarms," Fire Journal (NFPA) Jan/Feb:43-53 (1988).

10. Calcote, H.F., "Mechanisms of Soot Nucleation in Flames - A Critical Review," Combustion and Flame 42:215-242 (1981).

11. Calcote, H.F., "Why does Soot Inception Stop?," Combustion and Flame 71:105-106 (1988).

12. Place, E.R., and Weinberg, F.J., "The Nucleation of Flame Carbon by Ions and the Effect of Electric Fields," Eleventh Symposium (International) on Combustion, The Combustion Institute, Pittsburgh, PA, 1967, pp. 245-255.

13. Ball, R.T., and Howard, J.B., "Electric Charge of Carbon Particles in Flames," Thirteenth Symposium (International) on Combustion, The Combustion Institute, Pittsburgh, PA, 1971, pp. 353-362. 